\title{
ERRATUM
}

\section{A Study of Cultural Bias in Field Guide Determinations of Mushroom Edibility Using the Iconic Mushroom, Amanita muscaria, as an Example}

William Rubel ${ }^{*}, 1$ AND DAVID ARORA ${ }^{2}$

${ }^{1}$ Center for Cultural Studies, University of California, Santa Cruz, CA, USA

${ }^{2}$ Department of Forest Science, Oregon State University, Corvallis, OR, USA

${ }^{*}$ Corresponding author; e-mail: william@williamrubel.com

On the first page of the Appendix to this article (page 242, Volume 62, Number 3), third paragraph, third line, " $250 \mathrm{~g}$ " should be changed to " $110 \mathrm{~g}$ ".

A corrected online version of this article was posted February 24, 2009.

The authors regret the error. 